\title{
Experimental study of the dust-removal performance of a wet scrubber
}

\author{
Shengyong $\mathrm{Hu}^{1}\left(\mathbb{D} \cdot \mathrm{Yang} \mathrm{Gao}^{1} \cdot \mathrm{Guorui}_{\mathrm{Feng}}^{2,3} \cdot \mathrm{Fei} \mathrm{Hu}^{1} \cdot\right.$ Changhe Liu $^{4} \cdot$ \\ Jihua $\mathrm{Li}^{4}$
}

Received: 4 August 2020/Revised: 20 December 2020/Accepted: 13 January 2021 / Published online: 26 February 2021

(C) The Author(s) 2021

\begin{abstract}
A variety of dust control methods are often applied in coal mines, among which the application of wet scrubbers has proven to be an efficient technology for the removal of dust in airstreams, rather than diluting or confining the dust. In this paper, a wet scrubber design was developed. Based on a self-designed experimental test platform, the total dust concentration, respirable dust concentration, air volume, and average pressure drops of wet scrubbers with 12, 16, 20, and 24 blades were measured under different water intake conditions. The results show that the different water intake levels have only minimal effects on the air volume of the wet scrubbers. However, increased water intake had improved the dust removal efficiency of the wet scrubbers with the same number of blades. The wet scrubber with 16 blades was found to have the best dust removal efficiency at a water intake level of $1.35 \mathrm{~m}^{3} / \mathrm{h}$. Its total dust and respirable dust removal efficiency reached $96.81 \%$ and $95.59 \%$, respectively. The air volume was $200.4 \mathrm{~m}^{3} / \mathrm{min}$, and the average pressure drop was determined to be $169.4 \mathrm{~Pa}$. In addition, when the wet scrubber with 16 blades was applied in a coal preparation plant in China's Shanxi Province, it was observed that the total dust concentration had fallen below $8.1 \mathrm{mg} / \mathrm{m}^{3}$, and the respirable dust concentration had fallen below $5.9 \mathrm{mg} / \mathrm{m}^{3}$. Therefore, the results obtained in this research investigation provide important references for the use of wet scrubbers to improve coal production environmental conditions.
\end{abstract}

Keywords Coal mine Coal dust $\cdot$ Dust removal $\cdot$ Performance of wet scrubber

\section{Introduction}

In recent years, with the gradual improvements of mechanization and automation of the coal mine production in China, the dust-caused potential safety hazard and occupational health problems have become even more serious (Xu et al. 2017; Reed et al. 2019; Yao et al. 2020). At the production site of coal mine, high-concentration dust reduces the productivity of miners, affects output and benefit of the coal mine, and leads to death of the miners who suffer from the pneumoconiosis that cannot be cured for a long period, or leads to coal dust explosion and major accidents (Fan et al. 2018; Han et al. 2020). According to incomplete statistics, over the last decade, there is an increase of 98,648 pneumoconiosis cases in China's coal mines, with 19,657 cases resulting in fatality (Candra et al. 2014; Chen et al. 2018; Liu et al. 2017, 2018; Tan et al. 2020). Moreover, combustible dust is the main source of 
explosion accidents, $87.32 \%$ of China's 532 key coal mines are at risk for coal dust explosions ( $\mathrm{Li}$ et al. 2018). During the period ranging from 2000 to 2019 , there have been 16 dust explosion accidents in China's mines, resulting in 514 deaths (Zhou et al. 2018; Cheng et al. 2020). At the present time, among the many commonly used dust control methods, wet scrubbers have proven to be an effective and widely used technology in coal mines. Therefore, it was considered in this study that introducing improvements to the dust-removal performances of wet scrubbers in order to more effectively reduce dust concentrations during the production processes in the coal mines would be beneficial for protecting the occupational health of the miners and ensuring safe production activities.

Previously, researchers from home and abroad have been conducted extensive research on wet scrubbers. For example, Jiang et al. (1995) developed a self-excited water bath water-film dust remover which was considered to be suitable for the underground mine heading faces. Pak and Chang (2006) studied the collection efficiency by the computational model for gas-dust-liquid flow in venturi scrubber. Biswas et al. (2008) presented the hydrodynamic study of a counter-current spray column for the removal of particulates from gaseous wastes. Yuan et al. (2011) developed a high-efficiency wet dust collector with double "W" channel structure. Bal and Meikap $(2017,2018)$ used CFD simulation to predict the hydrodynamic characteristics of a venturi scrubber, and evaluated the performance of venturi scrubber for the remove iodine in filtered containment venting system. Wang et al. (2018) designed a venturi wet dust collector for mechanical casting workshops. Dong and Yang (2019) have conducted a considerable amount of research to assess the decontamination factors for wetscrubber FCVSs. However, due to the fact that the low dust removal efficiency of wet scrubbers, the development and application of wet scrubber technology in Chinese coal mines has been severely restricted. In addition, there have been few studies conducted regarding the simultaneous adjustments of the water intake levels and the number of wet scrubber blades, which could potentially improve the dust removal performances of the wet scrubbers. Therefore, this study considered it to be of major significance to improve the dust-removal performances of the currently applied wet scrubbers in order to reduce coal dust concentrations and protect the health of coal miners.

In this paper, a wet scrubber was developed, and the dust-removal performances of various wet scrubber were optimized based on a self-designed experimental platform. It was observed that under different water intake conditions, the total dust and respirable dust concentrations, air volume, and average pressure drops of wet scrubbers with different numbers of blades could be effectively tested. The best obtained dust removal efficiency was calculated, and the optimal number of blades for the most efficient wet scrubber design was determined. Based on the results of the above-mentioned experiments, an optimized wet scrubber was tested in a coal washing plant. It was found that its dust removal effects were significant. Therefore, this study successfully provided new ideas for improving the dustremoval performances of wet scrubbers in coal mines.

\section{Methodology using wet scrubbers}

\subsection{Design of wet scrubber}

Figure 1 shows a physical diagram of the improved wet scrubber which was used in this study's experimental testing processes. The wet scrubber was composed of water pipes, radial mixing impeller, motor, swirl blades, and dewatering grids. Among those, the water inlet pipe was a steel pipe with a diameter of $10 \mathrm{~mm}$. The radial mixing impeller was welded to both the water distribution plate and the blades, and the upper edges of blades were connected to the outer edges of the water distribution plate. The lower edges of the blades were connected to the bottom edge of the impeller. The diameter of the water distribution plate was $680 \mathrm{~mm}$. There were 16 blades in total, with lengths measuring $120 \mathrm{~mm}$, widths of $3 \mathrm{~mm}$, and angles of $45^{\circ}$. The bottom center of the impeller was connected to an explosion-proof motor. In the present study, a radial mixing impeller was used to provide negative pressure and water mist combined with dust. There were also six swirl vanes surrounding the shell of the explosion-proof motor at $45^{\circ}$ angles, which had the function of guiding the wind flow and providing centrifugal force. The design also included a dehydrator composed of 16 dewatering grids which surrounded the inner wall of a dewatering cylinder. This was used to separate the polluted water from the clean air in order to realize the dehydration of the coal dust-laden air.

\subsection{Purification principle of wet scrubber}

The principal mechanisms of for dust removal in a wet scrubber are inertial impaction, interception, and diffusion (Azzopardi et al. 1991; Goniva et al. 2009). Since wet scrubbers mainly rely on radial mixing impellers to complete the purification process, the role of the radial mixing impeller in this study's design was considered to be very important. In the majority of wet scrubber, inertial impaction, where the kinetic energy of the particle is used to penetrate the surface tension of the scrubbing liquid (water in most cases), is the dominant means of particle removal. Interception occurs when a dust particle makes contact with a liquid droplet at a lower relative velocity 

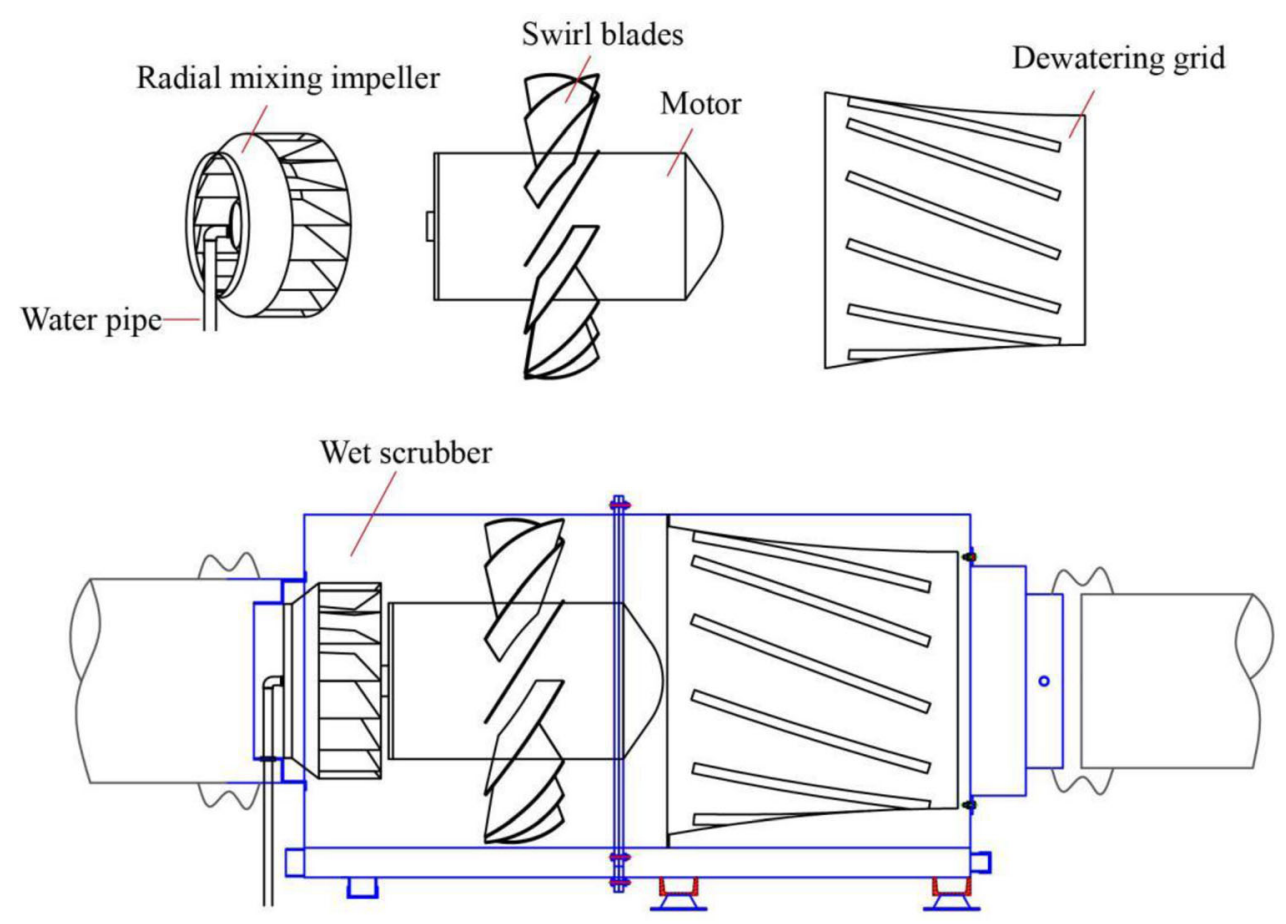

Fig. 1 Structure of the wet scrubber

than that required for impaction and adheres to the droplet surface. Diffusion, where particles migrate and come into contact with droplets due to gas density and turbulence fluctuations, is only important for extremely small particles $(<1 \mathrm{~mm}$ diameter) (David et al. 2011). Figure 2 shows purification process of a radial mixing impeller. When the wet scrubber is in operation, the radial mixing impeller is driven by the motors to rotate at high speeds, and water is sent to the centers of the water distribution plates through water inlet pipes. Then, under the actions of centrifugal force and gravity, the water moves to the edges of water distribution plate and enters the blade areas. The highspeed rotating blades breaks the water into water mist, and the water mist combines with dust and enters the interior parts of the blades. A portion of the water mist-dust mixture will then move horizontally along the blade rotation direction, and other portions will move perpendicular along the blade rotation direction. As a result, layers of liquid film will be formed on the inner surfaces of the blades. When this liquid film is affected by the impacts and
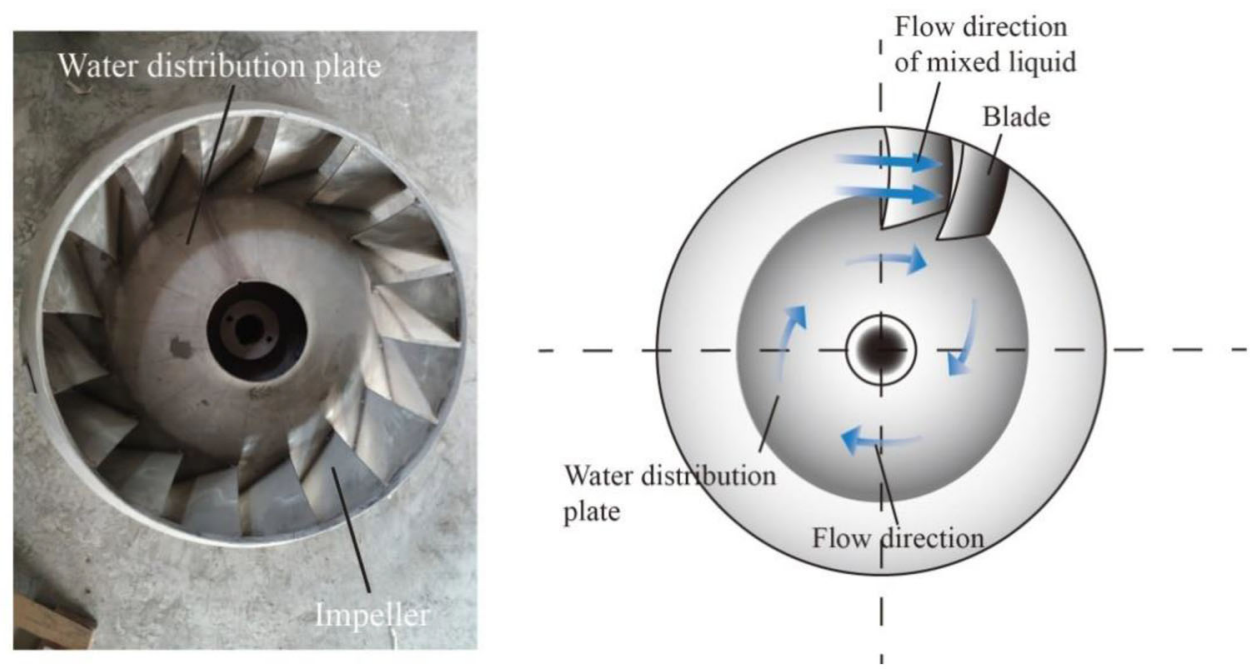

Fig. 2 Purification process of the impeller 
pressure of the dust and air while being subjected to centrifugal force, then inertial collision will form on the liquid film. Subsequently, the liquid film will break under the cutting action of the outer edges of the blades. This completes the atomization and interception processes and has been found to greatly enhance the chances of the water mist coming in contact with the dust particles.
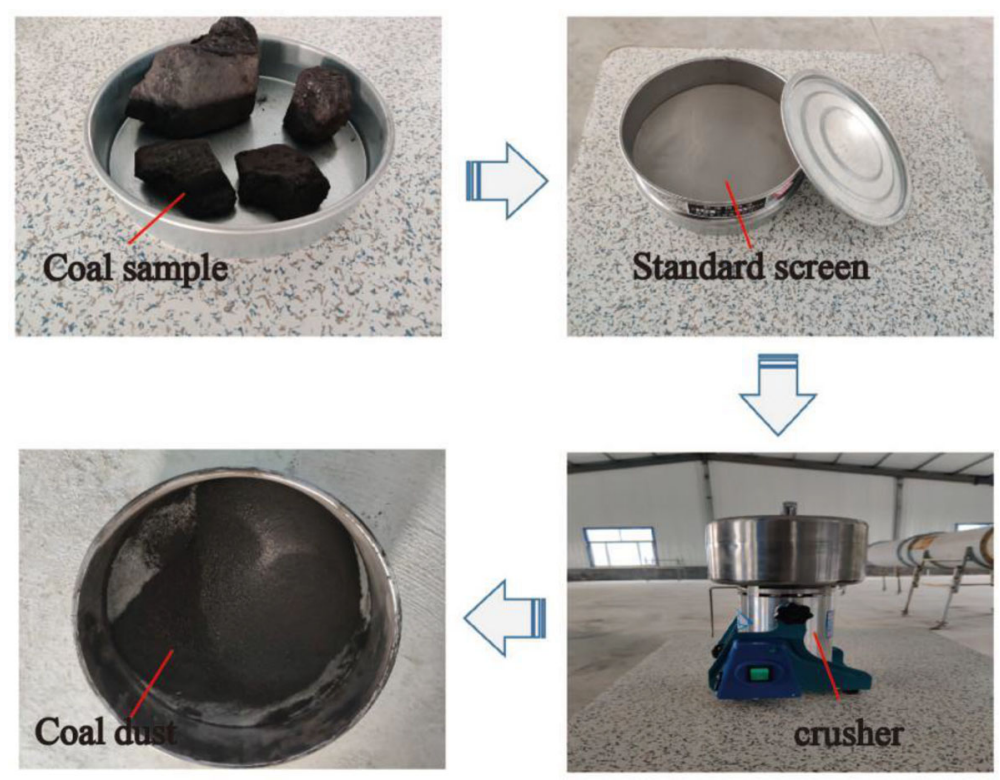

Fig. 3 Experimental materials

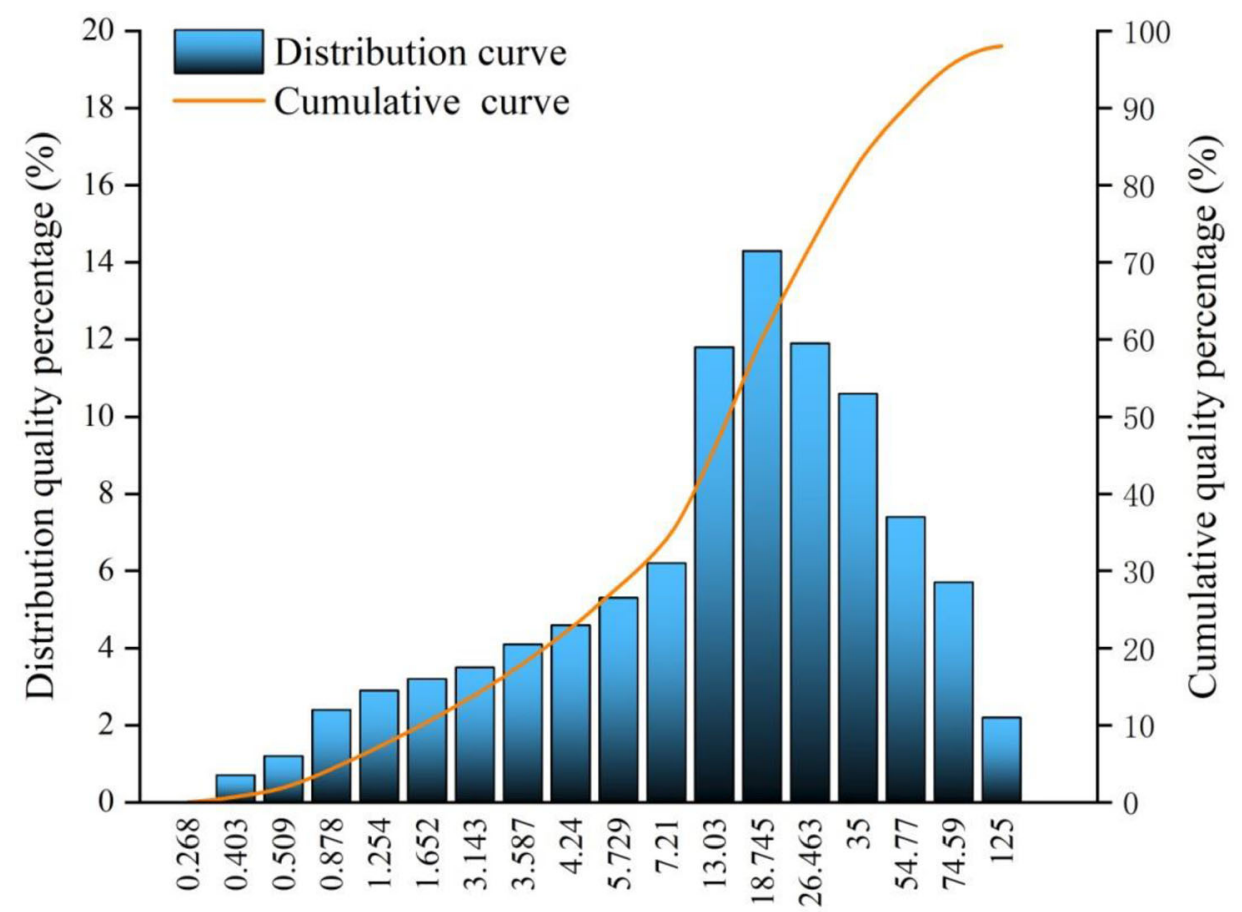

Coal dust particle size $(\mu \mathrm{m})$

Fig. 4 Particle size distribution diagram of the sieved coal dust 


\section{Experimental}

\subsection{Experimental materials}

Figure 3 shows the materials which were adopted for this study's experiments. The coal samples which were used in the testing processes were ordinary bituminous coal from the Jining No. 2 Coal Mine in Shandong Province, China. The standard inspection screen had 200 meshes. The rotation speed of the high-speed crusher was $24,000 \mathrm{r} / \mathrm{min}$, and the crushing mesh ranged between 60 and 200. The coal sample was crushed using a high-speed crusher and sieved through a standard inspection sieve in preparation for this study's experimental procedures.

In order to better verify the dust removal performance of the wet scrubber in the experiment, it is necessary to use the Malvern 3000 laser particle size analyzer to test the particle size distribution of the sieved coal dust. The test results of the dust particle size degree were statistically distributed, and finally the particle size distribution parameters were shown in Fig. 4. Coal dust particles are concentrated in $0.878-74.590 \mu \mathrm{m}$, and $13.03-35.00 \mu \mathrm{m}$ accounts for nearly half of all coal dust, about $95.8 \%$ was less than $74.59 \mu \mathrm{m}$. The test result is consistent with that the dust particle size after sieving by the 200-mesh standard inspection sieve was less than $75 \mu \mathrm{m}$.

\subsection{Experimental system}

Figure 5 illustrates the experimental system which was used to test the improved wet scrubber's performance. In accordance with the general technical conditions of the coal industry standard MT 159-2005 of the People's Republic of China, the inlet and outlet of the wet scrubber were connected to a wind tunnel with a length of $5 \mathrm{~m}$ and a diameter of $500 \mathrm{~mm}$. The experimental equipment also included a cyclone-fan test system composed of a supporting pitot tube, pressure sensor, and temperature and humidity sensors which was dedicated to evaluating the basic performance of the fan. All of the test program results for the system were collected and detected using computer software, and then calculated and displayed. During the testing processes, the cyclone-fan test system was connected to the wet scrubber, the temperature and humidity sensors were connected to the front and rear wind tunnel test rigs for the purpose of measuring the temperature and humidity of the entrance and exit of the experimental device. The aforementioned pitot tube was connected to the front wind tunnel according to the air intake pipe test bench. The "negative" connector of the empty box barometer in the cyclone-fan test system was connected to four pressure nozzles $(500 \mathrm{~mm}$ from the inlet) in the front

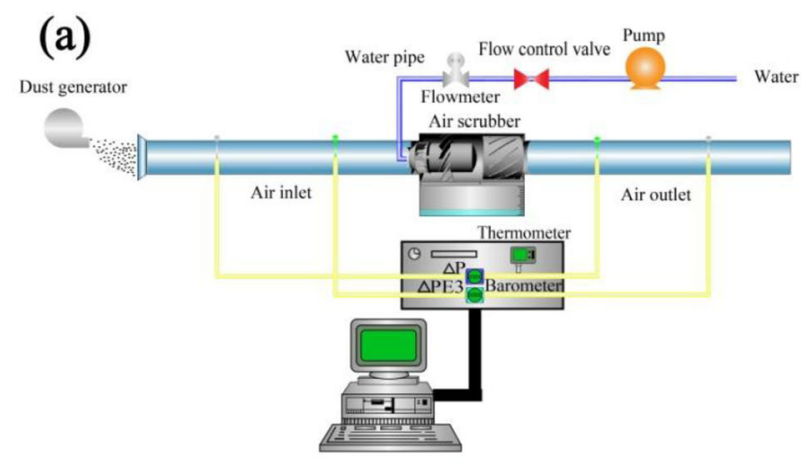

(b)

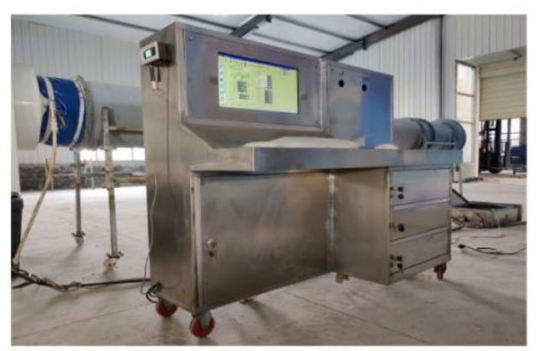

(c)

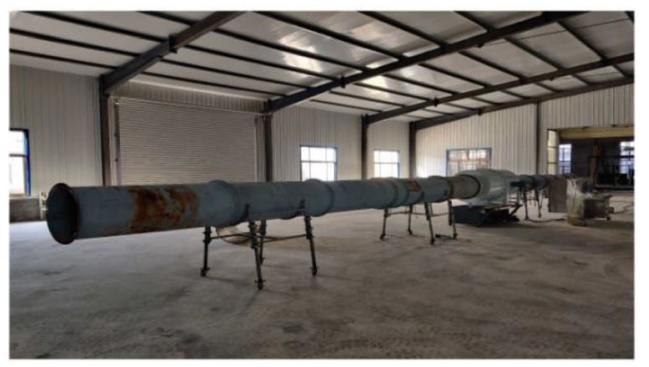

(d)

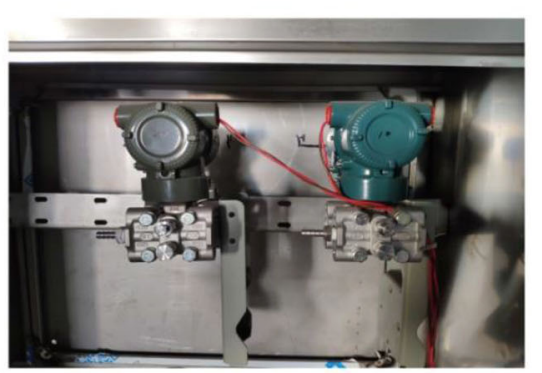

Fig. 5 Diagram of the experimental system. a Experimental system; b Cyclone-fan test system; c Wind tunnel; d Pressure gauge

wind tunnel test rig and rubber pipes were used to measure the static pressure. The "positive" and "negative" connectors of the pressure gauge in the cyclone-fan test system were connected to the total and static pressure ports of the pitot tube. This was then inserted into a hole in the outlet pipe located $4 \mathrm{~m}$ from the outlet of the extraction fan in order to measure the outlet dynamic pressure. In addition, the testing material also included a powder feeder (feeding 


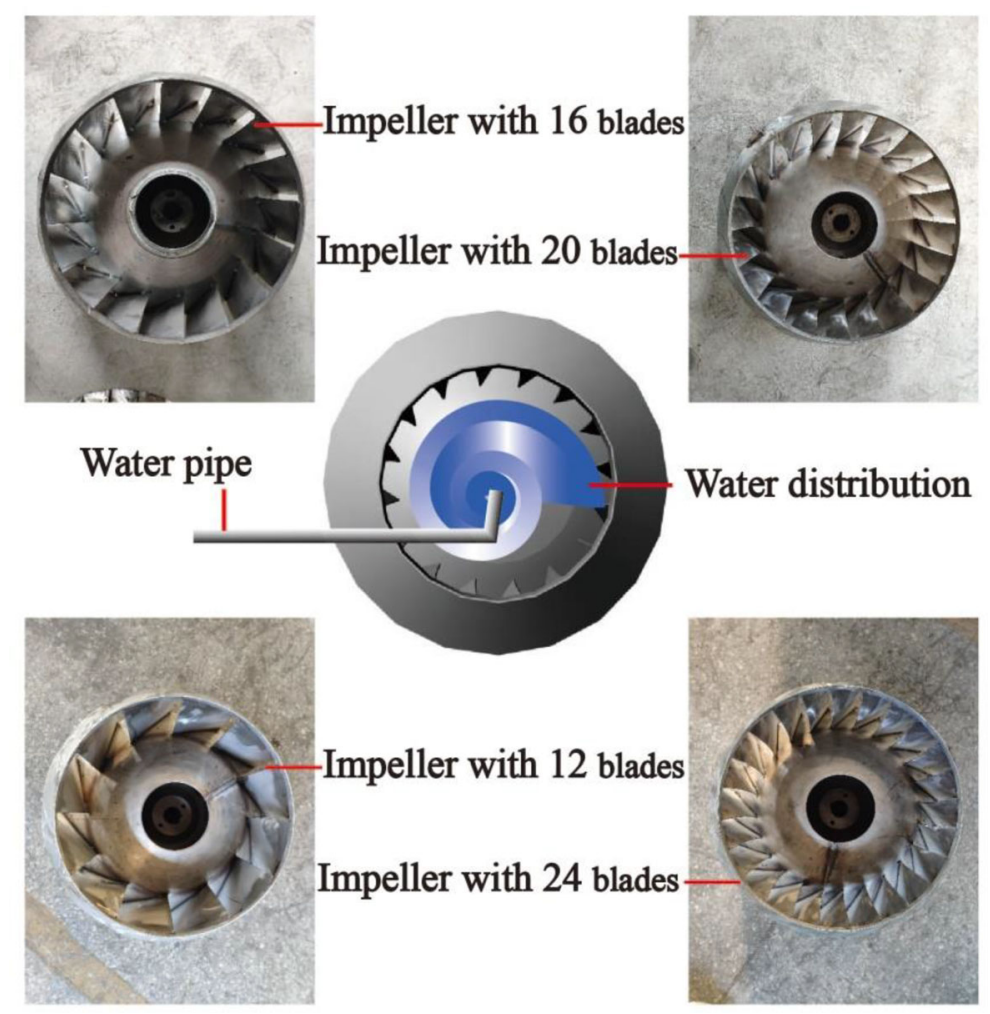

Fig. 6 Impeller images with different blade numbers

Table 1 Basic performance test value of impeller

\begin{tabular}{llllll}
\hline $\begin{array}{l}\text { Number of } \\
\text { blades }\end{array}$ & $\begin{array}{l}\text { Air volume }\left(\mathrm{m}^{3} /\right. \\
\mathrm{min})\end{array}$ & $\begin{array}{l}\text { Fan static pressure } \\
(\mathrm{Pa})\end{array}$ & $\begin{array}{l}\text { Fan dynamic pressure } \\
(\mathrm{Pa})\end{array}$ & $\begin{array}{l}\text { Relative humidity }(\mathrm{RH}) \\
(\%)\end{array}$ & $\begin{array}{l}\text { Atmospheric temperature } \\
\left({ }^{\circ} \mathrm{C}\right)\end{array}$ \\
\hline 12 & 165.4 & 1440 & 1870 & 52.9 & 16.3 \\
16 & 200.4 & 1150 & 2020 & 53.5 & 16.6 \\
20 & 147.4 & 1580 & 1730 & 52.3 & 16.4 \\
24 & 183.3 & 1300 & 2160 & 53.6 & 16.2 \\
\hline
\end{tabular}

speed of 0 to $3 \mathrm{~kg} / \mathrm{min}$ ), laser particle size analyzer, water meter (accuracy of $0.0001 \mathrm{~m}^{3}$ ), pumping pump, $90^{\circ}$ regulating valve, electronic balance (range of 0-300 g), and a stopwatch.

\subsection{Experimental methods}

During this study's experiments, the connections of each part of the test model were kept absolutely sealed in order to ensure that the air volume at the inlet and outlet remained the same. First of all, a CCZ20 mine dust sampler was prepared and blank filter membranes ( $\Phi 40$ and $\Phi 70$ $\mathrm{mm}$ ) were weighed and placed into a sampling funnel. Then, the pre-prepared pulverized coal sample was placed into a powder feeder and a total dust concentration of $480 \mathrm{mg} / \mathrm{m}^{3}$ and a respirable dust concentration of $280 \mathrm{mg} /$ $\mathrm{m}^{3}$ were release within $6 \mathrm{~min}$. The cyclone-fan test system was then connected to the wet scrubber, and the wet scrubber was put into operation. The water intake of the inlet pipe was adjust using a regulating valve, and the dust sampling process was adjusted to maintain iso-kinetic conditions after the system was determined to be running in a stable state. When the flowmeter of the instrument was maintained at $0.02 \mathrm{~m}^{3} / \mathrm{min}$, the powder feed was turned on and a stopwatch was used to start the timing process. During the testing procedure, the cyclone-fan test system had automatically recorded such data as the dynamic pressure, static pressure, and temperature and humidity values in the laboratory computer system, which was then used to process and calculate the data. Finally, after a duration of six minutes, the powder feeder, scrubber, and dust sampler were closed simultaneously. The filter 

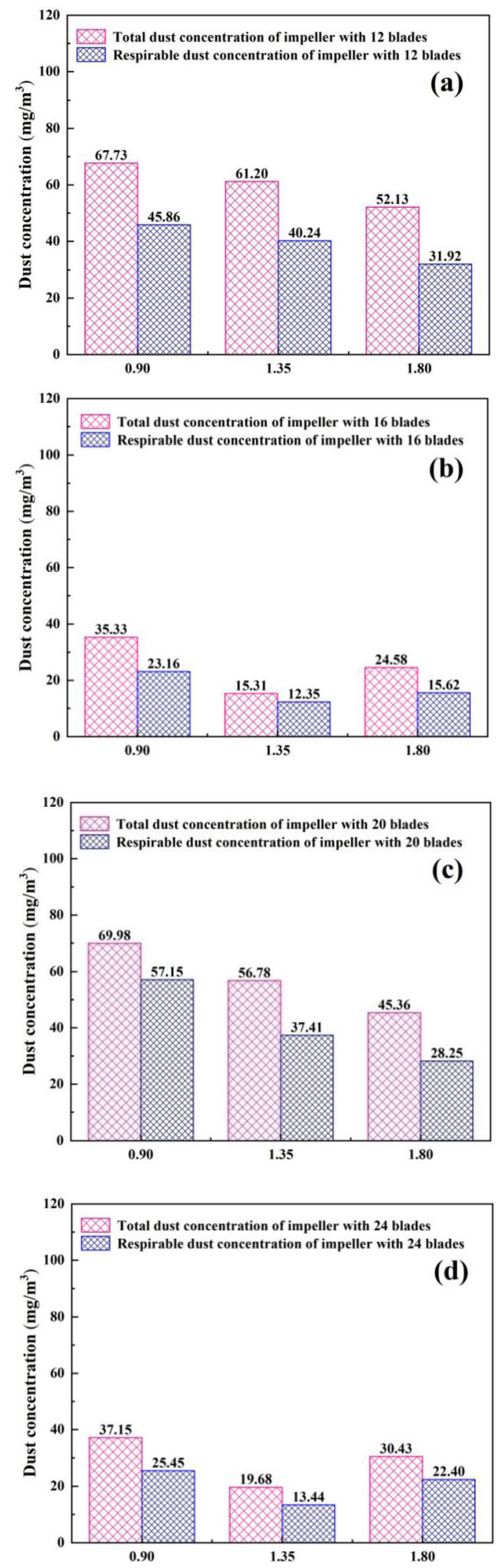

4Fig. 7 Dust concentration of impellers with different number of blades under different water intake. a 12 blades; b 16 blades; c 20 blades; $\mathbf{d} 24$ blades

membrane in the mine dust sampler was removed, dried, and weighed once again. The aforementioned experimental method was determined to have specifically described the specific process of the dust removal efficiency of the improved wet scrubber.

In order to fully verify the effects of the impeller on the dust removal efficiency of the improved wet scrubber, experimental tests on changing water intake and the number of impeller blades to improve the dust removal performance of the wet scrubber were conducted. As shown in Fig. 6, the number of blades of the impeller was changed to $12,16,20$, and 24 for this study's experimental tests. Under the same dust concentrations, this study changed the water intake of the water inlet pipe, and the effects of the different number of impeller blades on the total and respirable dust removal efficiency of the wet scrubber were investigated. In addition, the relationship between the dust removal efficiency and the air volume was analyzed. This research investigation conducted multiple experimental tests and calculation analyses of the air volume and dust collection efficiency, and the optimal water intake and number of blades of the wet scrubber were successfully determined.

\section{Results and discussion}

Table 1 details the basic performance parameters of the wet scrubber with different blade numbers which were experimentally tested in this study. It can be seen in the table that under similar test conditions, the air volume of the wet scrubber had also changed with the changes in the number of impeller blades, but had not increased linearly. The air volume of the impeller with different blade numbers was determined to be in the order of $16>24>12>20$. In contrast, when analyzed from the perspective of the fan static pressure, the impeller with 16 blades was found to have the lowest static pressure, and the impeller with 20 blades had the largest static pressure. These results had further verified that when the wind pressure value of the wet scrubber was constant, the static pressure was inversely proportional to the air volume.

After the basic performance tests of the wet scrubber were completed, the dust concentrations of wet scrubber were tested by adjusting the water intake levels. Figure 7a$\mathrm{d}$ details the total dust and respirable dust concentrations of the impellers with 12, 16, 20, and 24 blades under different water intake levels, respectively. It was found that within 
the allowable range of error, the water intake levels could be divided into three groups. The first group was $0.9 \mathrm{~m}^{3} / \mathrm{h}$; second group was $1.35 \mathrm{~m}^{3} / \mathrm{h}$; and the third group was 1.8 $\mathrm{m}^{3} / \mathrm{h}$. By calculating the average value of the total dust and respirable dust concentrations of each group, Fig. $7 \mathrm{~b}$ shows that when the water intake was $1.35 \mathrm{~m}^{3} / \mathrm{h}$, the total dust and respirable dust concentration of the impeller with 16 blades were the lowest, $15.31 \mathrm{mg} / \mathrm{m}^{3}$ and $12.35 \mathrm{mg} / \mathrm{m}^{3}$, respectively. In addition, the total dust and respirable concentrations of the impeller with 24 blades were also relatively low, $19.68 \mathrm{mg} / \mathrm{m}^{3}$ and $13.44 \mathrm{mg} / \mathrm{m}^{3}$, respectively. However, it was still impossible to determine the optimal number of blades for the impeller. It was necessary to further analyze the dust removal efficiency, air volume and average pressure drop of wet scrubbers with different numbers of blades.

As shown in Fig. 8, it was found that different water intake had only the smallest impact on the air volume of the novel wet scrubber. However, for wet scrubbers with the same number of blades, with the increase in water intake, the total dust and respirable dust removal efficiency of the wet scrubber gradually reached a significantly improved level. Figure $8 \mathrm{a}-\mathrm{c}$ shows that when the water intake is $0.9,1.35,1.8 \mathrm{~m}^{3} / \mathrm{h}$, the impeller with 16 blades shows the maximum air volume, total dust and respirable dust removal efficiency are the highest. In addition, the impeller with 24 blades also obtains higher total dust and respirable dust removal efficiency, but the processing air volume is relatively low. Therefore, under the same conditions, an impeller with 16 blades performs better. According to the theorem of moment of momentum (Eq. (1)), the one-dimensional steady flow can be derived to obtain Euler equations (Eqs. (2), (3)) of the impeller machinery:

$\mathrm{d} \frac{(m \vec{v} \times \vec{r})}{\mathrm{d} t}=M$

For one-dimensional steady flow:

$M=\dot{m}\left(v_{2 u} r_{2}-v_{1 u} r_{1}\right)$

where, $\dot{m}$ is the mass of gas passing through the inlet and outlet sections of the wet scrubber per unit time; $v_{1 u}$ and $v_{2 u}$ refer to the tangential component of the absolute velocity of the airflow at the inlet and outlet sections. Under the action of moment $M$, the work done by gas on the wet scrubber can be obtained by Euler equation (Eqs. (2), (3)) of the wet scrubber:

$L_{u}=v_{2 u} u_{2}-v_{1 u}$
Fig. 8 Dust removal efficiency and air volume under different water intake. a Water intake is $0.9 \mathrm{~m}^{3} / \mathrm{h}$; b Water intake is $1.35 \mathrm{~m}^{3} / \mathrm{h}$; c Water intake is $1.8 \mathrm{~m}^{3} / \mathrm{h}$

$$
\begin{aligned}
u_{1} & =\omega r_{1}=\omega \frac{n \pi D_{1}}{60} \\
u_{2} & =\omega r_{2}=\omega \frac{n \pi D_{2}}{60} \\
L_{u} & =\omega\left(v_{2 u} \frac{n \pi D_{1}}{60}-v_{1 u} \frac{n \pi D_{2}}{60}\right)
\end{aligned}
$$

In Eqs. (2) and (3), $L_{u}$ is the amount of work done on a gas of unit mass; $\omega$ is the angular velocity; $D_{1}$ and $D_{2}$ refer to the diameters of the wet scrubber inlet and outlet (Shu et al. 1991).

Therefore, the analysis of the gas-liquid two-phase interaction analysis in the wet scrubber through the above formula shows that when the water leaves the water distribution plate and enters the blades tangentially, the atomized water moves along the tangential direction of the blades. In the rotating area of the impeller, the water mist and gas are completely mixed. Under the action of highspeed rotating blades, on the one hand, the gas-liquid twophase moves horizontally along the direction of rotation of the impeller, and on the other hand, it moves in the direction perpendicular to the direction of rotation of the impeller. Due to the high-speed atomized liquid phase are dispersed behind the air phase and push the air phase forward tangentially at a higher tangential speed than the gas phase, thereby making full use of energy. The wet scrubber with 16 blades has a higher air volume and can be fully combined with coal dust.

In order to verify which scrubber with different blade numbers had achieved the best dust-removal performance, the average pressure drop values of the wet scrubbers with $12,16,20$, and 24 blades, respectively, were further studied. Figure 9 shows the average pressure drops of the wet scrubbers with different blade numbers. It can be seen in the figure that for the wet scrubber with the same number of blades, the average pressure drop value increased with the increases in the water intake. However, the increases were relatively small. It was found that for the same water intake, the magnitudes of the average pressure drop were $12>20>24>16$, respectively. This result was consistent with the air volumes of the wet scrubbers obtained in this study's experimental tests. This also further verified the above-mentioned Euler equation and the flow analysis theory of the air-liquid two-phase flow in the impeller of wet scrubber. When the tangential velocity of the liquid phase helped to increase the pressure of the air phase, the average pressure drop inside the wet scrubber was smaller and the air volume was larger. Therefore, it was found that 

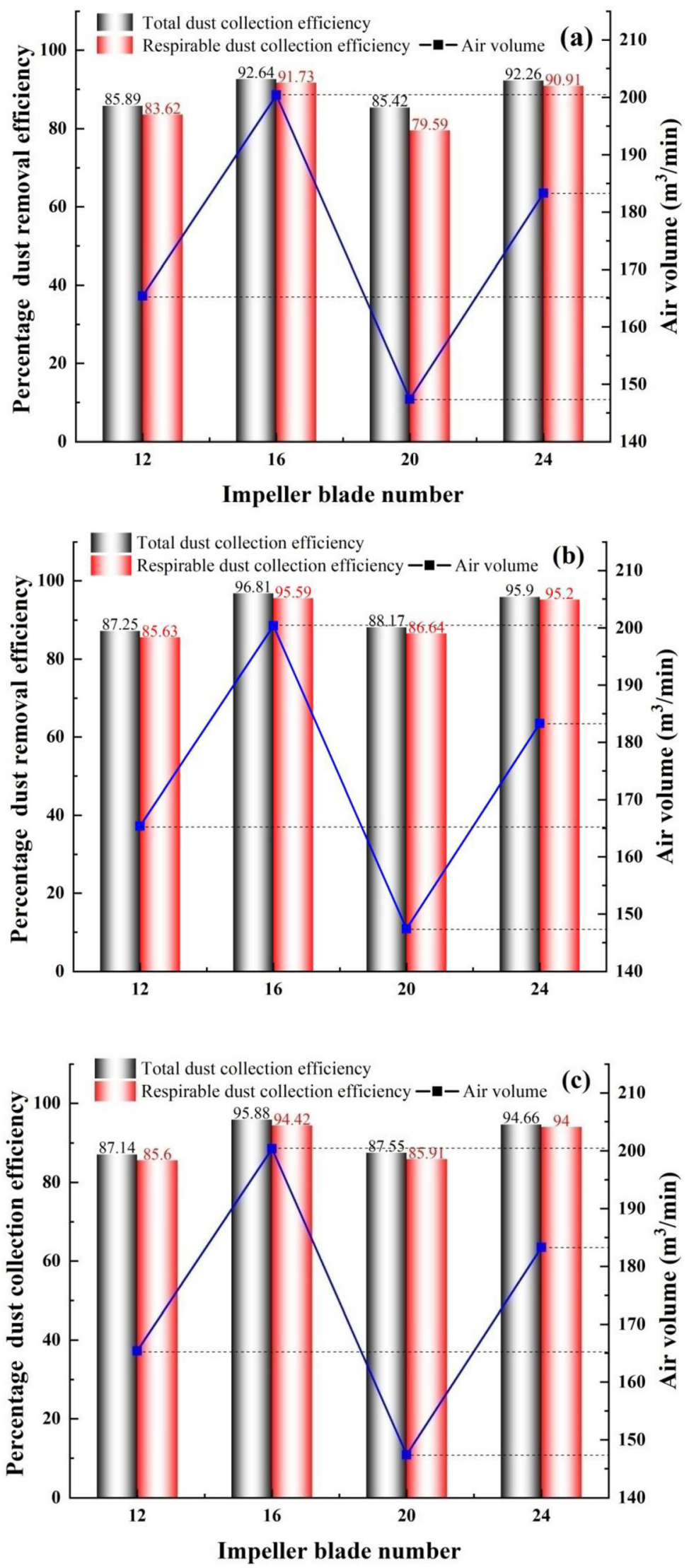


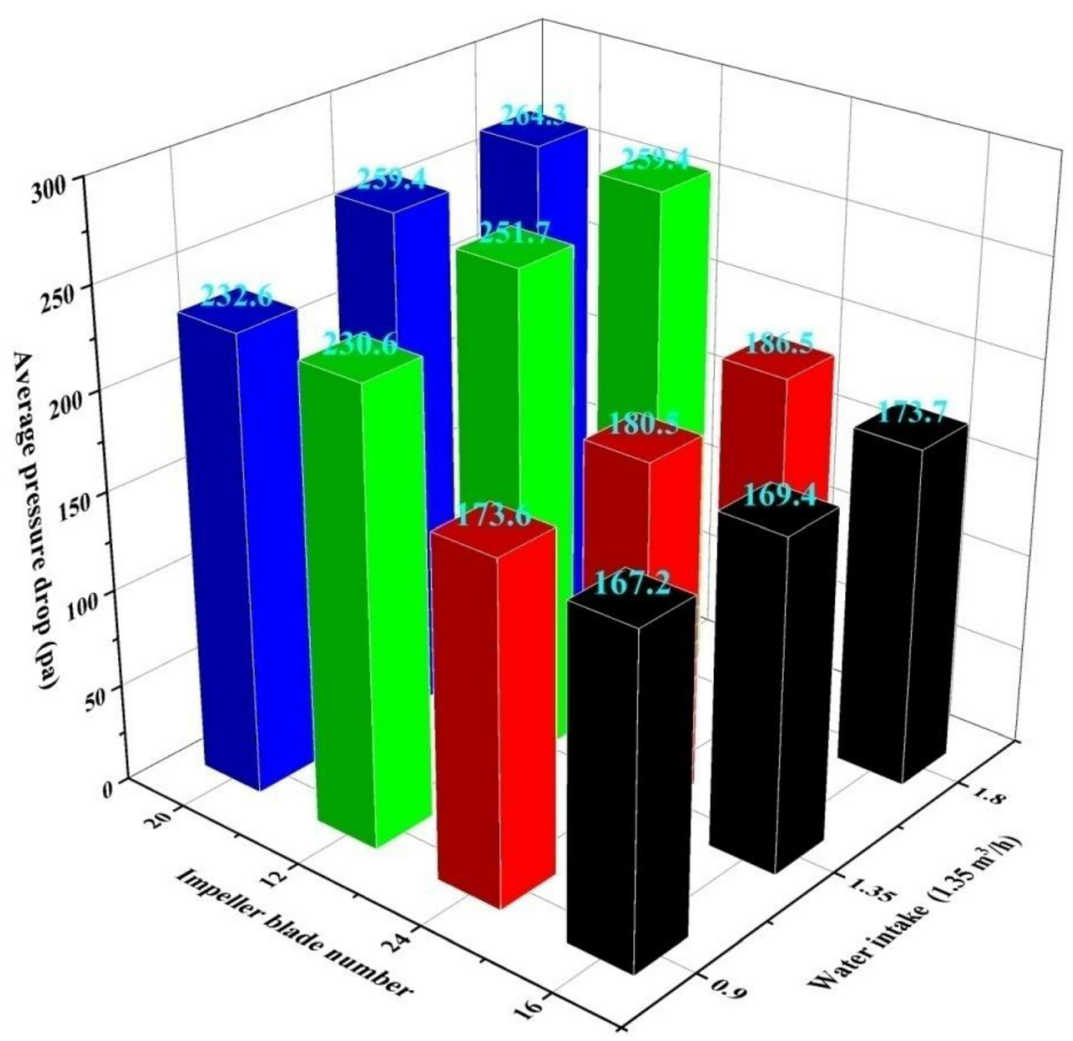

Fig. 9 Average pressure drop of wet scrubber with different impeller blades

a wet scrubber with 16 blades had the smallest average pressure drop and the largest air volume.

\section{Field applications}

It was decided in this study that the wet scrubber with 16 impeller blades was applied on-site at a coal preparation plant in China's Shanxi Province. The production capacity of the coal preparation plant was 5 million tons per year. The testing workshop was previously mainly used for the secondary dehydration and transportation of clean coal. It can be clearly observed in Fig. 10a that without the wet scrubber being used in this study's field applications. Due to the belt conveyor system generated a large amount of coal dust-laden air during its operation, and air renewal rate in the workshop of the coal preparation plant was slow, so the scattered dust could not be processed in a timely manner. This had resulted in large amounts of dust being diffused into the air which seriously polluted the environment of the workshop and posed a major threat to the health of the workers in the workshop. However, as shown in Fig. 10b, following the application of the modified wet scrubber, the visibility in the workshop was significantly improved. The workers' lines of sight were greatly improved due to the major reduction of visible dust particles in the air. The total dust and respirable dust concentrations in the workshop were tested, and the total dust concentrations were reduced from 89.7 and $90.2 \mathrm{mg} /$ $\mathrm{m}^{3}$ to 7.8 and $8.1 \mathrm{mg} / \mathrm{m}^{3}$, respectively. In addition, the respirable dust concentrations were reduced from 59.8 and $60.1 \mathrm{mg} / \mathrm{m}^{3}$ to 5.9 and $5.6 \mathrm{mg} / \mathrm{m}^{3}$, respectively, which reached the allowable concentration levels of dust particles specified in the National "Coal Mine Safety Regulations". As can be seen from this study's results, the dust removal effects were remarkable.

\section{Conclusions}

(1) Among the four examined wet scrubbers with different numbers of blades, the dust removal efficiency results of all the wet scrubbers were improved with the increases in the water intake levels. However, it was found that when the water intake was $1.35 \mathrm{~m}^{3} / \mathrm{h}$, the total dust and respirable dust removal efficiency of the wet scrubber with 16 blades was the highest.

(2) For wet scrubbers with the same number of blades, the average pressure drops increase with the increase in water intake. When the water intake was constant, the wet scrubber with 16 blades has the largest air 

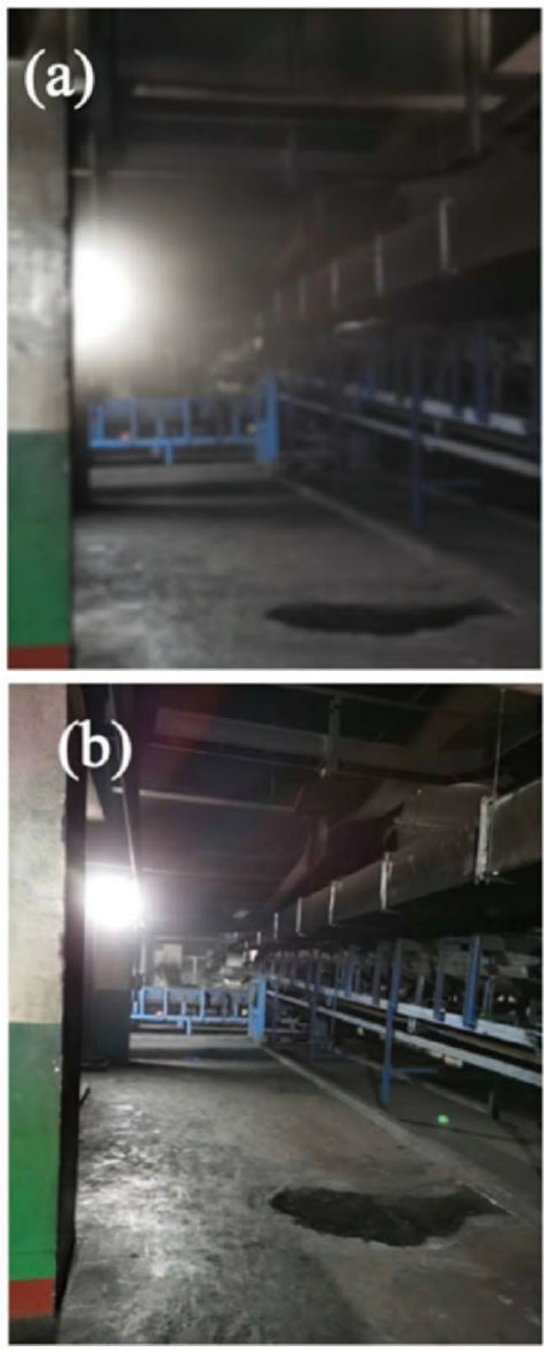

Fig. 10 Dust concentrations after using wet scrubber with 16 impeller blades at a coal preparation plant. a Wet scrubber is not used; $\mathbf{b}$ Field application of wet scrubber

volume and the smallest pressure drop compared to the other three types of wet scrubbers with blades.

(3) This research investigation conducted field tests used the wet scrubber with 16 blades on-site at a coal preparation plant in Shanxi, China. The results showed that the total dust concentration in the workshop of the coal washing plant had been successfully reduced to below $8.1 \mathrm{mg} / \mathrm{m}^{3}$, and the respirable dust concentration was reduced to below $5.9 \mathrm{mg} / \mathrm{m}^{3}$, the field application effect is remarkable.

Acknowledgements This research was supported by the Shanxi Province Colleges and Universities Science and Technology Achievement Transformation and Cultivation Project (2020CG008).

Open Access This article is licensed under a Creative Commons Attribution 4.0 International License, which permits use, sharing, adaptation, distribution and reproduction in any medium or format, as long as you give appropriate credit to the original author(s) and the source, provide a link to the Creative Commons licence, and indicate if changes were made. The images or other third party material in this article are included in the article's Creative Commons licence, unless indicated otherwise in a credit line to the material. If material is not included in the article's Creative Commons licence and your intended use is not permitted by statutory regulation or exceeds the permitted use, you will need to obtain permission directly from the copyright holder. To view a copy of this licence, visit http://creativecommons. org/licenses/by/4.0/.

\section{References}

Azzopardi BJ, Teixeira SFCF, Govan AH, Bott TR (1991) An improved model for pressure drop in venturi scrubbers. Process Saf Environ Prot 59:237-245

Chen LJ, Li PC, Liu GM, Cheng WM, Liu ZX (2018) Development of cement dust suppression technology during shotcrete in mine of China-a review. J Loss Prev Process Ind 55:232-242

Cheng WM, Zhou G, Chen LJ, Wang G, Nie W, Zhang QT (2020) Research progress and prospect of dust control theory and technology in China's coal mines in the past 20 years. Coal Sci Technol 48(2):1-20

Candra KJ, Pulung SA, Sadashiv MA (2014) Dust dispersion and management in underground mining faces. Int J Min Sci Technol 24:39-44

David C, Alley F (2011) Air pollution control, 4th edn. Waveland Press, Illinois

Dong S, Yang J (2019) Overview of the experimental studies and numerical simulations on the filtered containment venting systems with wet scrubbers. Ann Nucl Energy 132:461-485

Fan T, Zhou G, Wang J (2018) Preparation and characterization of a wetting-agglomeration-based hybrid coal dust suppressant. Process Saf Environ Prot 113:282-291

Goniva C, Tukovic Ž, Feilmayr C, Burgler T, Pirker S (2009) Simulation of off gas scrubbing by a combined EulerianLagrangian model. In 7th international conference on CFD in the minerals and process industries. Melbourne, Australia

Han H, Wang PF, Liu RH, Tian C (2020) Experimental study on atomization characteristics and dust-reduction performance of four common types of pressure nozzles in underground coal mines. Int J Coal Sci Technol 7(3):581-596.

Jiang ZA, Huang YP (1995) Experimental study on a new wet dust collector. Saf Coal Mines 9:2-5

Li QZ, Yuan CC, Tao QL, Zheng YN, Zhao Y (2018) Experimental analysis on postexplosion residues for evaluating coal dust explosion severity and flame propagation behaviors. Fuel 215(1):417-428

Liu GM, Cheng WM, Chen LJ (2017) Investigating and optimizing the mix proportion of pumping wet-mix shotcrete with polypropylene fiber. Constr Build Mater 150:14-23

Liu Z, Yang H, Wang W, Cheng WM, Xin L (2018) Experimental Study on the Pore Structure Fractals and Seepage Characteristics of a Coal Sample Around a Borehole in Coal Seam Water Infusion. Transp Porous Med 125:289-309

MT159-2005, Universal Technical Specification for Dust Collection Enginery for Mine, National Development and Reform Commission (in Chinese).

Manisha Bal BC, Meikap, (2017) Prediction of hydrodynamic characteristics of a venturi scrubber by using CFD simulation. S Afr J Chem Eng 24:222-231

Bal M, Reddy TT, Meikap BC (2018) Performance evaluation of venturi scrubber for the removal of iodine in filtered containment venting system. Chem Eng Res Des 138:158-167 
Pak SI, Chang KS (2006) Performance estimation of a venturi scrubber using a computational model for capturing dustparticles with liquid spray. J Hazard Mater 138:560-573

Reed WR, Joy GJ, Shahan M, Klima S, Ross G (2019) Laboratory results of a 3rd generation roof bolter canopy air curtain for respirable coal mine dust control. Int $\mathrm{J}$ Coal Sci Technol 6(1):15-26

Biswas S, Rajmohan B, Meikap BC (2008) Hydrodynamics characterization of a counter-current spray column for particulate scrubbing from flue gases. Asia-Pac J Chem Eng 3:544-549

Shu SZ, Zhu L (1991) Principles of Impeller Mechanism. Tsinghua University Press, Beijing

Tan B, Liu H, Xu B, Wang T (2020) Comparative study of the explosion pressure characteristics of micro- and nano- sized coal dust and methane-coal dust mixtures in a pipe. Int $\mathbf{J}$ Coal Sci Technol 7(1):68-78
Wang WQ (2018) Design and application of Venturi wet dust collector. China Foundry Mach Technol 53(5):77-79

Xu C, Zhou G, Qiu H (2017) Analysis of the microscopic mechanism of coal wettability evolution in different metamorphic states based on NMR and XPS experiments. Rsc Adv 7:47954-47965

Yao HF, Wang HY, Li Yanchuan, Lei J (2020) Three-dimensional spatial and temporal distributions of dust in roadway tunneling. Int J Coal Sci Technol 7(1):88-96

Yuan YP, Wang HN (2011) Study on efficient wet dust separator. Min Res Dev 31(03):51-54

Zhou G, Ma YL, Fan T, Wang G (2018) Preparation and characteristics of a multifunctional dust suppressant with agglomeration and wettability performance used in coal mine. Chem Eng Res Des 132:729-742 